\title{
Potemkin Fabrications: Administrative Gymnastics, Messy Boundaries, and the Alternative Facts that Enable Design-Build Pedagogy
}

\section{MICHAEL HUGHES}

American University of Sharjah

EMILY BAKER

University of Arkansas

\section{INTRODUCTION}

Celebrated as a mechanism for engaging 'real' projects much of the contemporary design-build literature foregrounds the action-learning embedded in the physical act of making a piece of architecture at full-scale. Participating students and faculty comments regularly highlight the direct encounter with the materials and method of construction as well as the collaborative, cross-disciplinary nature of community engagement. Brian Mackay-Lyons, founder of the Ghost Lab in Nova Scotia, argues that "Pragmatism is the best teacher" and "Technology is best learned by making" and he links design-build to, "The apprenticeship model of architectural education-its roots in the master-builder tradition of the Middle Ages." (Mackay-Lyons 2008, p 135 and p138) However, the conventional fixation on the construction process and final products obscures the complex, often unappetizing, 'behind the scenes' logistics necessary to implement, and sustain, new pedagogies.

In the spirit of Anthony Bourdain's expose, Kitchen Confidential, which revealed secrets of the restaurant industry, this paper examines the unseen, generally unspoken compromises, contortions and ethical dilemmas confronting design-build faculty as they navigate the numerous, often mutually exclusive, structural gaps separating normative university culture and the pedagogy of full-scale making. It is easy to see that facilities present challenges as lecture halls do not accommodate construction equipment and design studios are ill-suited to material acquisition, storage and assembly, but the more insidious challenges reside in policy handbooks that establish standard teaching load formulas, accredited curricula requirements, grant guidelines and tenure processes. Sizable financial budgets require accounting while extraordinary time commitments combined with legal concerns at the administrative level conspire against widespread implementation while liability concerns and academic calendars present additional obstacles. Simply put, design-build does not fit neatly within the Academy.

Beyond the Academy the myriad of preparatory negotiations related to funding, partnership agreements and legal considerations conceal much of the infrastructural logistics from participating students. The involvement of property owners, stakeholders, department administrators,
RICK SOMMERFELD

University of Colorado-Denver

MO ZELL

University of Wisconsin-Milwaukee

university officials and lawyers, and municipalities suggests the extent to which external contingencies and extensive dialogue shape student projects. The process of project acquisition and preparation can take months to complete. These preparations typically occur before students even enroll in the course.

In the face of these challenges faculty may be forced to limit the project scope, employ external assistance and/or take on inappropriate liability to increase the likelihood of 'successful' project completion. In more extreme circumstances faculty may conspire, with or without the explicit approval from their Dept. Head or Dean, to manipulate course schedules, coerce participation outside regular class times, create skeleton syllabi to provide participants with additional credit hours or ignore safety concerns. Similarly, administrators have been known to redirect departmental resources, provide unofficial incentives, manipulate teaching loads and cover-up for inexperienced faculty to preserve the appearance of success.

Exposing these hidden truths and discussing them openly can illuminate the real costs borne by participating faculty and programs while simultaneously enabling a safer, more transparent and ultimately sustainable academic structure that acknowledges the fundamental difference between traditional and experimental approaches.

\section{SQUARE PEG, ROUND HOLE}

To be blunt, design-build studios do not fit in the contemporary university. It is not a close fit or even only slightly awkward, but rather a radical misalignment at the level of fundamentals. Georgia Tech Professor Jude LeBlanc once remarked that design-build, "...is like running an architecture firm with 12 people who know nothing about the practice of architecture while simultaneously running a construction company with the same 12 people who know nothing about construction". While both accurate and illuminating Prof. LeBlanc's observation highlights only those challenges internal to the project team and relative to the scope of the building project. Institutional practices honed to deliver normative curricula and traditional scholarship in an efficient manner present more numerous and insidious obstacles as outlined above. 
The formula linking credit hours, content, FTE and NAAB SPCS operates within a M/W/F or T/Th schedule of 50 or 75-minute classes distributed across a 15 week semester. The formula is not designed for courses that need to meet 4 to 8 hours per day 3 to 6 days per week for one or more semesters. It is no accident that design-build at Yale and Auburn began far from their home campus.

Ultimately, whether they happen on campus or in exile, during the normal academic year or in the summer the fact that design-build studios happen is, in every instance, a minor miracle enabled not by divine or administrative grace but by various combinations of naiveté, ignorance, ingenuity, interpersonal skill, deceit, leadership, risk taking and wizardry possessed by the individual faculty, or faculty teams, leading the projects. The enterprise can be made easier or more difficulty by the degree of flexibility, good will and/or blindness characterizing a specific institutional context and administrative culture, but ultimately design-build faculty bear the burdens endemic to the disjunction between pedagogical structure and institutional context.

\section{INCREMENTAL SOLUTIONS}

Given the inhospitable context how, exactly, do these minor miracles occur? The challenges, if not impossibilities, are clear yet somehow the projects have been completed. What is the nature of the wizardry employed? Similar to the transformation of carbon into diamonds, sheer pressure drives much of the design-build magic. It is difficult to overstate the multiple stresses imposed by colleagues, administrators, collaborators, clients, budgets and schedules all compounded by the fact that failure will forever by borne, solely, by the faculty. Further, as tenure and promotion depend on peer reviewed scholarship and the awards commonly sought by DB faculty depend on stellar outcomes it is not difficult to understand the incentive to stray beyond conventional notions of propriety.

The near impossibility of the challenge spawns adaptation and invention. Individual faculty develop tactical strategies that incrementally ease project implementation in the long run with the aim of creating a more strategic and sustainable structure for design-build pedagogy over the long term. Presented as series of partial remedies developed by four experienced, design-build faculty teaching at different schools the following case studies highlight specific challenges and discrete solutions employed in particular, localized situations.

\section{CASE STUDY 01: SMALL + FAST}

In an attempt to avoid logistical challenges associated with traditional design-build studios, the projects offered at the University of Wisconsin-Milwaukee focus on full-scale but temporary structures that emphasize performative material characteristics and experiential activity in the urban realm. On the whole, they are smaller, cheaper and faster than typical design-build projects.
That said, impermanence has its disadvantages. The inherent nature of installations necessitates that they be un-installed after their completion. The end of the project build marks the completion of the installation but not the end of the work. Installations must be dismantled and removed, but once the project is complete, grades are in, and documentary photos have been added to the portfolio there is little incentive for students to help with the clean-up. As a result, the faculty member is often left to organize a new project in which student volunteers and/or paid laborers complete the tear down.

The shift to temporary installations alleviated many of the traditional design-build challenges, however, the challenge of locating sites and partners persisted. As it turns out permitting and liability concerns remain largely the same for both temporary installations and permanent structures. As a result, the need to move swiftly to occupy sites is often derailed by the need to involve the legal department and risk management team at the university. Surprisingly the college administration suggested pursuing a guerrilla-style operation under the mantra of asking for forgiveness instead of permission. After addressing the concerns of the more risk-averse students expressed regarding potential arrests or incarceration for trespassing on private property the plan worked and 13 temporary installations were completed across the city in one day.

\section{INTERIOR PARTNERSHIPS}

To combat these challenges the installation projects have moved indoors and consistent funding has been secured from a committed partner. In addition to funding this partner provides dedicated space at their facility 6 miles north of campus while also actively participating by guiding the students through material research and on-site training. Now the projects are completed in one semester without the need for illegal occupation. From day one students know the location and size of their site as well as the budget assigned to their installation.

As evidence of their investment in the project, our partner takes care of project demolition at the end of the semester and they have accepted the liability associated with students working on their property. However, to reduce responsibility they have requested that onsite fabrication be reduced in favor of pre-fabrication in the school's woodshop.

\section{CASE STUDY 02: PROTOTYPING AND THE IMPACT OF INSTITUTIONAL CONTEXTS}

Prototyping is a method of deepening the investigation of material systems, fabrication processes, computational methods and choreographies of construction while overcoming, to some extent, the logistical hurdles involved with larger design-build exercises. Prototyping courses can operate independently, without the expectation of application in service of some future project or as the precursor to a subsequent design-build semester. In either case prototyping 
provides a venue to test innovative and/or alternative systems of structure and assembly that engage emerging technologies. While potentially alleviating the onus of designing and building a finished work within a single semester or academic year, a prototyping studio can still engage real clients and user needs while allowing students to learn through full-scale building.

Testing multiple design alternatives within a bracketed topic expands the conversation around options within the studio and allows the client to see a range of potentials for their project with less financial investment upfront. Prototypes provide evidence of the viability of the proposal to clients and administrators and buoy the confidence of students and faculty while allowing for much more accurate cost and time estimates in projects that push the bounds of normative construction.

Prototyping and iterative refinement of a material system allows novice students to learn fabrication skills and hone craft while also gaining material intuition and learning the language of a construction process in a context where failure is not detrimental. This allowance for failure is rare in conventional design-build projects where client needs and the academic calendar conspire to limit the student's development in favor of simply finishing.

\section{AUDI-FAB}

Audi-Fab Acoustic Interiors began with a "prototyping semester" followed by a "build semester". Initially four student teams spent the fall semester, in consultation with professional acoustic engineers, developing acoustically absorbent and diffusing interior material systems through full-scale prototypes that employed advanced fabrication. While the process elevated the onus of producing a fully developed project within a single semester there was an added responsibility as the instructor had to lead four very different projects to a high level of resolution- no small feat.

Another issue to overcome is the potential discrepancy between the broad learning opportunities provided by the prototyping semester and the more production-oriented work required when the focus shifted to a single, fully developed project build the following semester. Once a single prototype was chosen for development and implementation the work became more repetitive and production-oriented. This was in large part motivated by the need to complete the project on time and on budget amplified by the perceived scrutiny and performance evaluation that accompanies a junior faculty doing their first design-build project at a new school.

The ultimate success of the Audi-Fab sequence came down to sheer force of will on the part of the faculty member combined with administrative support for an inexperienced design-build teacher inclusive of a flexible funding framework that is perhaps unique to private institutions.

\section{INSTITUTIONAL CONTEXT}

A second prototyping course, taught at a public university, revealed challenges not directly linked to prototyping. In this example a partnership with a local children's museum led to an examination of new design solutions for play, seating and artwork in outdoor spaces. The partnering organization provided $\$ 4000$, but accessing the funds was delayed for months due to inconsistent, often conflicting guidelines within the university's accounting mechanisms. Navigating the university bureaucracy required untold hours despite the fact that the school had a long history of design-build projects. The bureaucracy delayed certain aspects of prototyping and led to both the faculty and students paying for materials out of pocket.

In addition, the faculty endured additional pressure in the form of skepticism from colleagues from within the department ahead of the faculty member's upcoming tenure case. This departmental context led to the faculty accepting a proposed increase in the planned output of the studio. The initial budget was adequate for two large prototypes, but the faculty was pressured to accommodate six groups each working on their own prototypes. Not surprisingly the added scope led to budget overruns. Unlike the private university, this state institution had no capacity to fund the additional costs. As a result, overruns had to be covered by the professor and the funding partner.

Further complications resulted from physical location of the fabrication lab. While the lab was well stocked and spacious the off-campus location further isolated the new design-build faculty member from their colleagues and similarly isolated the participating students from the broad academic life back at the school. The physical distance created additional challenges for final reviews when university bureaucracy interfered with the transport and display of the completed work on campus.

These examples highlight the need for administrative support in predicting and addressing institutional systems before projects begin. Accounting processes, contracts, risk assessment, liability and intellectual property need to be discussed and thought through carefully to ensure that course objectives can be met. At the same time inflexible institutional requirements can limit the department's ability to engage contemporary teaching methods and modes of production.

Ultimately, prototyping provides a promising option for engaging experimental and emerging technologies and methods within a design/build context, but only when the institution is willing to design the robust yet flexible frameworks required by alternative coursework.

\section{CASE STUDY 03: INSTITUTION BUILDING}

Many design-build programs operate with no departmental support, no slush fund, and no contingency plan. A single error could bankrupt the program or individual, end a career, 
or leave clients with half-built projects. Programs with no money often borrow tools from their shop, and seldom return them in the condition they were checked out. These actions put non-tenured faculty at risk and burden departments with additional expenses that are not directly paid for by those enrolled in design-build.

Despite offering design-build courses since 1992 CU Denver is not immune to these issues. Over three years, 2009-2011, the University of Colorado hired two non-tenured professional practitioners to help deliver the design-build studio and associated construction class. This was an attempt to bridge a gap left by a departing tenured faculty member. In two out of the next three years, the project funding was pulled by the client well into the semester. With student learning on the line and without reserve funds available from the college, the faculty were forced to pull money out of their firms to pay for the project (2010) or abandon the project entirely (2011).

This unsustainable trajectory led to a fundamental shift in how CU thought about funding and leadership. CU Denver pivoted away from conventional budget models linked to on-campus enrollment and established the Colorado Building Workshop as an "extended studies" enterprise. Similar to study abroad, the extended studies budget formula allowed the design-build program to collect all student tuition and then pay an 30\% tax to the university. The remaining $70 \%$ would be controlled by ColoradoBuildingWorkshop. The economic freedom provided by this model allows for the investment into faculty, staff, consultants, tools, travel, marketing, and a contingency fund. To manage these funds CU Denver committed to appointing a Director of the Design-Build Certificate program.

This fiscal autonomy and leadership insulate ColoradoBuildingWorkshop from faculty who view design-build as a liability to departmental resources. The financial flexibility allows ColoradoBuildingWorkshop to invest in projects that may be underfunded, aid in developing new methods of fabrication, or cover project overages. Additionally, the budget allows us to set aside funds to cover unexpected contingencies.

\section{THE ILLUSION OF OUTPUT}

ColoradoBuildingWorkshop has developed new ways to effectively stretch the academic calendar to give the illusion of a larger projects being completed in a short duration. In the first years of the program participating faculty were eager to show that design-build could be a repeatable model so they initiated multiple projects at the same time. Some projects came together quickly while others take years to develop as clients raise money, search for land, or require city officials to approve work to expedite permits. ColoradoBuildingWorkshop has found this time invaluable. Taking a year or two to collect data and understand constraints uncovers hidden issues that wreak havoc within the confines of a semester. If projects are not fully developed, they can be shelved for a year to allow the funding, permitting, project scope, or timeframes to more fully develop.

The illusion of projects with a broad scope is further masked by the relatively uncomplicated nature of the projects themselves. While it is true that CBW built 14 cabins for Colorado Outward Bound in 19 weeks with 28 students, the uninsulated 200 square foot cabins lack water, heating, or lighting and the foundations were completed before the students engaged in the project. Additionally, a series of standardized details combined with a restricted material palette and prefabrication methods conspired to limit on-site construction. This example does not dismiss the logistical nightmare of the build, but rather illustrates the importance of due diligence before the semester beginning.

\section{CASE STUDY 04: CONSTRUCTING A COLLABORATIVE CURRICULUM}

The primary challenge to programs is the lack of integration of design/build activities into the overall curriculum. Ultimately, a lack of integration and lack of institutional support can lead to the marginalization of both the design/build program and the involved faculty.... The stresses upon faculty caused by excessive workloads, multiple roles, and expanding student numbers and project scope threaten structural collapse.

\section{—G. Gjertson, 2011 ACSA Fall Conference Proceedings.}

As Design-Build evolved through the 1990's and early 2000's most schools came to rely on a single individual to deliver full-scale course content and design-build programs became synonymous with individual faculty-Dan Rockhill at Kansas, Mary Hardin at Arizona, Dan Hoffman at Cranbrook, etc. This format concentrates the design-build burden on one faculty while causing challenges at the administrative level relative to faculty burnout, departmental politics and overall program sustainability.

Responding to these challenges, in 2010 faculty in the Department of Architecture at AUS began work on an alternative approach to design-build featuring a collaborative teaching model and an iterative course sequence. As a young school without the weight of institutional tradition faculty at AUS were free to imagine and implement a sequence of courses formulated to introduce and embed tactile, full-scale learning opportunities across all levels of an undergraduate design curriculum located in a region unaccustomed to haptic production. The resulting curriculum distills lessons from advanced design-build courses and distributes them throughout the architecture course sequence in order to better prepare students for the complexities of full-scale DB projects. 
The structure of the new design-build program follows the convention common to most undergraduate universities in which the basic concepts presented in introductory, 100-level courses become progressively more advanced and focused as students proceed through the curriculum to 400- and 500level courses. While this approach is conventional, and may even appear obvious, it is surprisingly without precedent in design-build education where projects happen almost exclusively at the advanced level such that students enrolled typically engage the complexities of a full-scale project for the first time in an advanced 400- or 500-level studio and they do so without prior preparation.

In parallel to the curricular development strategic hires resulted in a team of six to eight participating faculty in both Architecture and Interior Design who animate the curriculum with projects that range from one week to one year in duration and often blur the boundary between analog and digital techniques. In this team-based approach to course delivery no individual faculty member teaches a fabrication or DB course each semester. As a result, members of the DB team are also fully integrated members of the faculty engaged in the entire BArch curriculum who regularly teach non-DB courses. In addition, the relatively large number of faculty participating in DB provides for an unusual degree of diversity both in terms of project type/scope/scale, aesthetic predilections, and outcomes.

\section{CONCLUSION}

In his 2011 paper, House Divided: Challenges to Design/ Build from Within, Geoff Gjertson proposes that, “...design/ build studios should be a required part of the curriculum of all architecture programs. Until faculty and administrations make this determination and the ACSA and NAAB promote and require this change, design/build will always be marginalized." Given the insights outlined in the bulk of the text above the current gap between the realities faced by designbuild faculty and the idea of requiring a design-build studio experience for every architecture student is, to put it mildly, immense. Implementation would necessitate wholesale and radical changes to current teaching and administrative norms as the numbers of participating students would rise by at least $300 \%$ with a parallel expansion of related logistic and administrative hurdles.

Each university has particular, if not peculiar, expectations, internal logistics and traditions that exert unique challenges on faculty, particularly new faculty, seeking to engage in designbuild pedagogy. Where design-build is well established at a particular institution it can be difficult to modify the local status quo. Conversely, at institutions where design-build is not well established, or where the institutional infrastructure is not structured to address the non-normative teaching model faculty encounter nebulous guidelines and inconsistent institutional guidance.
Before we imagine a future in which all students, and many more faculty, participate in design-build we must confront existing challenges. Beyond wholesale change a more nuanced approach aimed at resolving, or alleviating, existing challenges might include expanding the range of full-scale learning options, developing alternatives to administrative and financial structures and articulating goals more precisely. As it stands, we do not even have a common vocabulary to define what we mean by 'design-build' in terms of scope, project type, and intended learning outcomes.

As suggested by the case studies in this paper, wrestling with the challenges presented by this still new sub-discipline requires comprehensive and inventive thinking to ensure that design-build education evolves into a viable, sustainable component of the curriculum.

\section{ENDNOTES}

1. Brian Mackay-Lyons, Ghost: Building an Architectural Vision. (Princeton: Princeton Architectural Press, 2008), 135 and 138

2. Geoff Gjertson, "House Divided: Challenges to Design/Build from Within," in 2011 ACSA Fall Conference Proceedings. (Washington, DC: ACSA, 2011) 